When the political becomes personal: reflecting on disability bioethics

Tom Shakespeare, Norwich Medical School, University of East Anglia

\title{
Introduction
}

In the Venn diagram of identities and practices, there is clearly an overlap between academic and activist. Many academics are not activists; most activists are not academics. But a significant number of people have dual roles. Feminist thinkers have bridged the gap between activism and academia; so have LGBTI scholars; so have post-colonial and antiracist thinkers and doers. Most of these movements and ways of thinking have abandoned the historic split between the personal and the political, or the public and the private. Partly this is because the personal is political. If you are spending your working hours thinking through oppression and resistance to it, you are not likely to be someone who never does joins a protest, never writes a letter of complaint, never organises for a better world, let alone someone who lives an unequal or exploitative life. To do less would be hypocrisy. So disability scholars and campaigners are wheeling a path made easier by the efforts and activities of others.

Engaged scholars have sought consistency in their thinking and their positions. They want to put their politics where their profession is. Which raises a question of how to reconcile these two identities or practices. Are they separate? That is to say, does the academic work nine to five each week day, and the activist come out at night and weekends? Are they different activities, requiring different positions and possibly contradictory? Or, like Marx's romantic picture in the German Ideology, are they all part of the whole? Some of us tend to write about what we know: the gay scholar who lives a gay life and writes about sexuality; the feminist who seeks a personal as well as a professional transformation of gender relations; the disability scholar who writes about bodies and minds that differ from the norm and who seeks to change perceptions nd practices in the public domain.

But an activist academic or an academic activist is not just the person who goes from the protest to the lecture room or library. There are also those who go the other way, or rather 
who move from the faculty into the public forum. They are academic activists. So this paper will consider this move also, because otherwise I am only problematizing activism, and not academia itself, which seems to me easy and wrong.

So, in this paper, I explore this debate in the most personal terms, and without apology. First, I give my own story. Then I explore questions of how people think through bioethics issues, speaking of both academics and lay people. Next, I consider the particular obligations which those of us who claim to be intellectuals may lay ourselves open to. Finally, I say something about disability bioethics.

\section{Mea culpa}

I came into thinking and writing about prenatal diagnosis and selective termination and genetics from a commitment to disability rights, and from personal experience of having an inherited impairment. At the time of my early advocacy, and then my first academic paper in 1995, I had two young children with achondroplasia, the condition I had inherited from my own father. To me, life as a disabled person was positive, and we were equally valid to non-disabled people. In 1988, when my partner had been pregnant with Ivy, we had come up against obstetricians who advised us to have diagnosis and termination if the pregnancy was affected by achondroplasia. We also encountered eugenic thinking from family members and friends. My concern was that prenatal screening and selective termination were an assault on viability of disabled people and their right to exist.

Between 1989 - 1994, I was writing my doctoral thesis, exploring ways of thinking about disability, drawing on many different areas of sociology, political thought and cultural analysis, and trying to make links to feminist thinking and that of other liberation struggles. So in the time period I am discussing here, I was a fledgling academic, exploring what it all meant. I had originally started my PhD not because I wanted to be an academic but because I wanted to write a book about disability, which I wanted to call The Politics of Physical Difference: I ended up with a doctorate, but no book.

In 1995/1996, I authored a Channel 4 television documentary with the director Sarah Boston - who herself had personal experience of having a son with Down syndrome who 
sad. Our film, Ivy's Genes, looked at the issue of prenatal diagnosis through the eyes of Ivy, then eight years old. In the film, I drew comparisons with eugenics.

But as part of the film, and to achieve more balance, I was asked to do an interview with Professor John Burn, a clinical geneticist wo was head of the Northern Genetics Service. John had thought a lot about these issues too, and was a very good doctor with a strong commitment to his patients. He challenged me to think about the doctors and scientists who worked for his service, but above all, the women who were asking for, and receiving, prenatal diagnosis, some of whom were making difficult decisions to have terminations of wanted pregnancies. This was a perspective that until then I had not made space for in my thinking - although I did support a woman's right to choose. So as a result of spending time with John and his colleagues, I had to let go of this idea that doctors were all directive, that their thinking was eugenic, that they were part of a programme to eliminate disability.

Around this time, too, a colleague of mine quietly told me about a mutual friend, a woman who had become pregnant at the age of 40 . She had received a diagnosis of Down syndrome. She and her older husband, who had been positive about the pregnancy, reluctantly felt that they did not have the emotional resources and were too old to parent a child with Down syndrome, and reached the very difficult decision to have a termination. I could see the logic of their thinking. I could not describe it as eugenic. More importantly, I worried about the documentary and the public statements I had made, and the papers I had published: would someone like her, seeing this material, feel worse about the decision she had made? That was not my intention. Indeed, I felt strongly that I did not have the right to tell people that they were wrong. Perhaps partly this was because my training was as a sociologist, not an ethicist. We are socialised to look at systems and structures. We are not always as comfortable looking at individual actions. And we are not trained to make normative statements about these actions: we shy away from those judgements. Although often we are happily critical about representations, or discourses, or social programmes. A third thing that happened around this time was that I had more encounters with moral philosophers and bioethicists. I debated with John Harris, Jonathan Glover, Julian Savulescu and others in Britain and Australia. I would go on to meet Dan Brock and David Wasserman and colleagues in America. I read about the non-identity problem. I realised that my position on prenatal diagnosis and selective termination - and indeed, that of activists in 
general - concealed contradictions, inconsistencies and other problems of logic. If I presented it in debate with the bioethicists, I would easily be defeated.

As a result of all these experiences, exposures and thinking, I moved away from the strong activist position I had first espoused. I developed a more nuanced analysis. I focused more on the context in which screening took place - the lack of balanced information, the risk of directiveness, the way that the screening offer was staged, like a conveyor belt, so that women and men ended up in a place which they may not have chosen at the start. I was still critical of the practice of prenatal diagnosis, but I was much more careful about my language, and the analogies I was drawing, and what it was that I was criticising.

In a sense, this was like the journey I went on around theories of disability and the social model. When I started my PhD in 1988, I was very excited about disability rights and the politics of disability. But the more I thought, the more I became disillusioned with the social model of disability. When Michael Oliver's book, The Politics of Disablement, came out in 1990, I was as critical as I was enthusiastic. When Jenny Morris' book, Pride Against Prejudice, was published in 1991, I was much more enthusiastic, and wrote the one and only fan letter I have ever sent to a researcher. I ended up having a more nuanced and critical position on models of disability, which led to the revisionist article that Nick Watson and I wrote in 2001 (which was rejected by the leading disability studies academic journal on what we believed were ideological grounds) and then to Disability Rights and Wrongs in 2006. This marked a break with the social model orthodoxy of the dominant materialist approach to disability studies (Shakespeare, 2014). It also made me unpopular with my former allies.

Thinking of bioethics, at a personal level, I still felt drawn to working on genetics. I was having health problems, and commuting to Leeds was too difficult. And I had had big clashes with Colin Barnes, whose position seemed to be orthodox Marxism and endorsement of the UPIAS social model position.

For these three reasons, I jumped at the opportunity of being the first employee of the Policy, Ethics and Life Sciences Research Institute (the acronym PEALS was John Burn's brain wave) at the International Centre for Life, in Newcastle. The International Centre for Life, which I had written a critical article about of back in 1997, was the brainchild of Alastair 
Balls and Linda Conlon, late of the Tyne and Wear Development Corporation. It brought together a science visitor centre; the NHS Northern Genetics Service and the regional IVF service; commercial enterprises in biosciences. Alastair was keen for there to be a bioethics component to complete the multi-disciplinary picture, and hence PEALS came into being, and I began work in October 1999.

This was not a popular move. Local disability rights activists - associated with Disability Action North East, an organisation I had founded with Stuart Bracking in 1992 - daubed swastikas on the billboards outside the building, and the slogan "No Nazi eugenics". When I took the job, the Disability Now newspaper quoted activists accusing me of selling out, of compromising my principles for the sake of a cushy job. An article in Coalition, the magazine of the Greater Manchester Coalition of Disabled People - the ideological heartland of the disability rights movement - accused me of supporting eugenics, and of being no better than Peter Singer, the notorious utilitarian bioethicist and hate figure for the disability community.

Being attacked by people who I had always regarded as my friends was very hurtful, and the unfairness of the language and the comparisons drawn stung. I was used to having supporters in the disability community, who cheered speeches and comedy routines. Now I had detractors, critics, haters even. I realised that there was a cost when you abandoned a clear cut, polarised position. You lost your constituency, your people disowned you. It was a lonely place, to be critical of the social model and to be thoughtful about all the perspectives in prenatal diagnosis. Ironically, by the end of the 1990s, I felt closer to the philosophers than to activists. But I was not one thing or another: too nuanced to be an activist, not sufficiently well argued to be a philosopher.

I may not have pleased disability rights activists with my position, but I do not think I had retreated into my ivory tower (or Sir Terry Farrell-designed Millennnum Commission-funded white elephant by the Tyne). My public engagement included policy work. Around this time, I was briefly a member of the Antenatal Sub Group of the NHS National Screening Committee, and I remember arguing strongly in terms of the target of the screening programme being the number of women who made an informed decision, not the number of women who terminated their pregnancy. My work also included patient education. While at PEALS, I received a grant from the Wellcome Trust to create a website to give 
women and men balanced information about Down syndrome and other conditions which were tested for during pregnancy. So I tried to put my intellectual work into practice, albeit differently to have the disability rights community may have preferred, but perhaps more constructively.

Later on, I would go through a similar process with another key issue in bioethics, assisted dying. The disability rights movement have been uniformly opposed. But I thought about it extensively, and read arguments and evidence. I felt that the disability rights movement were not being consistent. The political principle of choice and control was central to the independent living movement's thinking. So why would this be abandoned at the end of life? If someone was terminally ill, and wished to have assistance to die, why was this choice the only one that the disability rights community would not endorse? The idea that this decision was taken because of lack of support to live independently in the community did not seem relevant. Independent living and personal assistance was hardly relevant to someone in the end stages of cancer or motor neurone disease. Moreover, I looked at the data on what ordinary disabled people - not activists but the person in the street - thought about assisted dying. This suggested that, like the non-disabled public, there were a range of positions. Disabled people were similar to non-disabled people - in opinion polls, the majority supported the right to assisted dying, within carefully regulated parameters. This became my position, and lead to more disagreements with the disability rights movement. Ironically, the one other prominent activist who took a public stance in support of assisted dying was the very same individual who had written the unpleasant piece in Coalition magazine accusing me of being like Peter Singer.

This time around, there were limits to my public stance on assisted dying. The pressure group Dignity in Dying asked me to be a patron of their disability caucus, an invitation which I refused. While I was happy to speak out in support of assisted dying (in limited circumstances) and to write articles and participate in debates, I did not want to be so closely associated with another unpopular (to disability rights activsts) position. It gets exhausting always to be defending oneself, and to be regarded as a traitor by your natural constituency. Perhaps this could be regarded as cowardice. 


\section{Ways of thinking, ways of knowing}

In trying to consider what it meant to be an academic, and why this meant taking positions in opposition to the disability rights movement, I found the work of the psychologist Jonathan Haidt very appealing, when I was introduced to it by Jackie Leach Scully. In what he himself calls his most important paper (Haidt 2001), he looks at the rational and the intuitive, and distinguishes between two ways in which people think. The first is our image of thinking. He describes the judge, who explores all the evidence, and weighs it up carefully, before coming to her opinion. The second is our more likely practice of thinking. He describes the barrister, who knows the position he wants to adopt in advance, and then selects the evidence to support his intuitions. Most lay people, Haidt argues, are more like barristers and judges. We have biases, we don't want to shift our position when new evidence comes to like, we are stubborn in our prejudices.

I think this descriptive analysis is similar to, but different from, R.M.Hare's two-level utilitarianism, which distinguishes between everyday intutition and special case critical deliberation (Hare 1981), although it has some similarities, and the 'thinking fast/thinking slow' model that Amos Tvesrky and Daniel Kahnemann developed (Kahnemann 2011)

As an academic, and without being appallingly pompous, I think my duty is to be a judge. If new evidence or argument comes to light, which is irreconcilable with my current position, but nonetheless robust, then I have to change my position. Otherwise I am not being faithful to my duty, which is an honest and open commitment to the truth, or at least, the closest I can come to truth at any moment.

An activist does not have this responsibility. It may be useful for her to take a hard-line position, because it shocks others into reconsidering their own positions. She may want to generalise, rather than talking in detail. She will probably need some slogans, preferably short enough to fit onto a placard or tee-shirt. She will certainly want to motivate people, inspiring them to fight injustice. For all of this, simplicity is useful, complexity is not. Dichotomies are useful, multiple stakeholders are not. Clarity is vital, nuance is not. So we have to consider whether, at any one time, we are being judges or barristers: will we strive for what is true, even if it is inconvenient, or for what is supportive of a political position? Politics can suborn rationality. People want to hold a position, even if it is not 
supported by evidence and argument. But intellectual honesty takes you away from rigidity, away from certainty, into grey areas, and might take you into areas which are unpopular. I remember encountering this issue when I first started challenging the social model of disability, in the early 1990s. I was with a political friend, who was out in public promoting this dichotomous, simple, easy to understand account of disability. Later, we were back at his house, and discussing our aches and pains, as happens when two or more disabled friends get together. I asked him something like: how come you can support the social model, and deny that disability has anything to do with impairment, given that you admit that all these issues are important in your life? And he replied that different contexts and different audiences demanded different responses: he saw no contradiction between the two positions that he held. But for me, perhaps because my primary persona was an academic, while his primary persona was as an activist and community organiser, it was vital that I could hold positions that were consistent and as truthful to the world as I understood it as possible.

Of course, some activists aspire to, and mainly achieve, the judge-like position; some academics consciously or unconsciously end up as barristers. And others take up different positions regarding the evidence and arguments at different times and on different topics. It usually does not matter, if you are a barrister and end up being a judge: in the real world, some barristers do end up on the judicial bench (I believe it would be wonderful if more activists were judges, and I feel our politics would go better if they were). But in the real world, judges do not go back to being barristers. The metaphor is telling us something here. If one is going to set oneself up as a judge, have to be very sure that one has all the information and has weighed it appropriately. This claim to truth is serious and significant matter.

I believe that some academic bioethicists believe they are being judges, but are actually being barristers. They have a set of intuitions, and they construct papers which apply those intuitions to different topics, drawing on their philosophical training to give the reasons and arguments which those intuitions require to become intellectually robust positions, rather than mere prejudices.

Of course, some academics have a more complex account of truth than my simple model here. They might scoff at my naivete. If they are relativist or believe that truth is a socially 
constructed concept, or have some other slippery or contingent notion, perhaps they do not have these dilemmas, and can reconcile their different positions without losing sleep. But I am not one of those academics.

There have been multiple times when I got it wrong, when I discovered new facts about the world, or understood new arguments, and those have always been shaming moments for me: I feel I should have known this already. How could I opine as an academic, when I did not know that about disability? This is particularly difficult, because unlike many academics, I talk about more topics than just my particular area of expertise. I go on public radio or a current affairs programme, and answer questions about art and religion and politics, which have nothing to do with disability and on which I am not qualified to speak as an academic. I think at this point I am being a public intellectual. I am still doing my best to be as accurate as I know how, but my words should not be given much more credence than those of other folks. Only on my specialist subject should I be thought judge-like.

My career has been one of an activist who becomes more and more engaged in academic topics, who becomes a qualified sociologist, but at the same time becomes more philosophically literate, and then shares what he has learned with his constituency. Unlike my work as a sociologist, I am not expecting to make significant contributions to bioethics, let alone moral philosophy. In ethics, my primary audience is people equally untrained in philosophy. By writing and speaking publicly, I have tried to raise the tone of the debate in activist circles and among the wider public. I have challenged what I see as inconsistencies and other failures of logic in what otherwise might seem very appealing and resonant positions. I want activists to become better at what they do, to refine their arguments and focus their attacks. Some of the things they might think are problematic, I think are less worrying. Other issues that are not problematized, I would like to challenge.

However, I would like to say that as an activist turned bioethicist, I do have something to contribute to bioethics debate. So what might that be? I have lived experience which I am willing to think about, and share explicitly. I was born with one impairment (achondroplasia) and acquired another (spinal cord injury) in my forties. So I know something about whether impairment is identity-affecting, and in what ways (Edwards). I also know what these impairments are like, although it is always possible that mine is a unique and unrepresentative experience: I can supplement my subjective expertise by 
experience by knowledge of the wider social and psychological research on these conditions, some of which I have generated. (Shakespeare et al 2010). I have had two children, each of whom shares my genetic condition, so I understand at first-hand what it is like to have a diagnosis in pregnancy, and the pressures to which that exposes you - from clinicians, from lay people. I have had a partner who had a termination on the grounds of foetal anomaly. I have had a partner who has undergone assisted conception. I have supported several people with terminal illness. Throughout my life, I have had friends with Down syndrome, and have personally supported children and supported adults with the condition. In other words, I have expertise from experience, as well as academic expertise. Jackie Leach Scully (2008) talks about "disability bioethics", the particular perspectives which someone with lived experience as well as academic training can bring. Perhaps, like her, I epitomize that. Most philosophers or bioethicists or social scientists or policy-makers have experienced some of what I have just described: they have had abortions and had children, they have been relatives or friends of people with disabilities, they have supported people at the end of life. So my life experience here is far from unique. The only dimension that is different is our lived experience of disability, which most philosophers or bioethics or policy-makers tend not to have had, because disabled people remain largely excluded from these debates, at the highest level. The person, like Scully Adrienne Asch or myself, who combines academic training, knowledge of bioethics, and lived experience is rare.

This means that at best, my papers on bioethical themes, however idiosyncratic, may have perspectives which are useful, in combining expertise by experience with some academic expertise. Or else, more worryingly, perhaps I know enough philosophy to be damaging, and retain enough activist, to make trouble: in other words, the worst of both worlds. But more than publications, perhaps my contribution best lies in the public sphere. So when I chair a Nuffield Council on Bioethics enquiry, or make a television documentary, or speak to a Minister or a parliamentary select committee, I can bring a distinctive combination of knowledge and experience, which may be more refined and accurate than either the academic or the activist, and may also have greater rhetorical power. I join the ranks of the engaged academics, whom we might also call activist academics. 


\section{Philosophical expertise and public debate}

The activist-academic is a common role, particularly in bioethics. Many bioethicists and philosophers have contributed to public policy debate. They may have sat on, or even chaired, government enquiries (on various topics of law reform, or inquiries into abuses) or advisory deliberations (such as Nuffield Council on Bioethics or Hastings Center). They may have contributed to public education in various ways (talking in the media, talking in schools, talking at café scientifiques, writing for popular readers). Their motivations for these activities may be various, and not always benign: not just raising the tone of the debate, or even resolving complex problems of bioethics or political philosophy in the real world,, but also feeling the satisfaction of being a public figure or wielding power.

There is a very small literature on the activist-philosopher. One debate is the question of whether someone can have moral expertise, and what that might consist of. Moreno (2006), 706) suggests that moral expertise is something to which we should aspire. It consists of knowledge of general principles and moral theories; together with thinking skills; together with a refusal to take the easy way out. In particular this last issue supports my claim about bioethicists being judges above. Dan Brock says something similar:

"Truth is the central virtue of scholarly work. Scholars are taught to follow arguments and evidence where they lead without regard for the social consequences of doing so" (Brock 2006, 715)

Yet just as freedom of speech does not include shouting "Fire!" in a crowded theatre, so there is a requirement of caution when it comes to saying everything that could be said about a topic. Brock points out that when a bioethicist is working in the public arena, she should be thinking about the impact of her words, not just the truth claims she is making.

“... persons who directly participate in the formation of public policy would be irresponsible if they did not focus their concerns on how their actions will affect policy and how that policy will in turn affect people." (Brock 2006, 716)

So in the world of policy and practice, there are useful fudges that avoid worse outcomes: Brock gives the example of the distinction between killing and letting die. One could argue 
that acts and omissions with the same consequences are morally the same, but this might lead to worse outcomes in the world of clinical medicine.

Brock concludes that academic bioethicists should participate in public policy, but should be prepare to take limited and temporary positions which may be incompatible with their wider intellectual agendas. If the bioethicist is to have an impact, he needs to hedge and trim somewhat - as opposed to what he might say in a university seminar - in order not to be rejected as eccentric or appalling. The point of participation in policy is to persuade nonacademics of a position, not to maintain the pious and pure position of integrity and truth.

To understand some of the benefits and dangers of activist-philosophers, next I want to outline, as I perceive them, some of the main varieties of activist-philosopher. These are ideal types, illustrated with reference to some individuals who perhaps epitomise the type.

First, there is the hyper-liberal. Almost everyone, in Britain at least, is liberal to some extent. We support freedom of speech, we are pluralist when it comes to religion, we want to be agnostic about how people live their lives, as long as they do not infringe the rights of others. But our polity also has certain ideas about what activities are better than others. We want to limit people's freedoms in various ways: we wish them to wear seat belts, we do not want them to buy sex, we want them to eat better. In the past, governments imposed some of these preferences via the law: abortion and homosexuality and pornography were banned or censored to improve public morality. Now we leave many of these choices up to individuals. So our polity has become more liberal, but not perfectly liberal. The philosopher as hyper-liberal acts to brush aside the remaining shreds of paternalism, pointing out inconsistencies in regulation. For example, I believe Jonathan Woolf played this role on the Gambling Review Body (2000-2001) which recommended deregulation of the gambling industry and which led to the New Labour government creating one of the most liberal environment for gambling in the world. By 2015, nearly two thirds of Britons had gambled in the previous year; and nearly $4 \%$ could be classified as "at risk" gamblers (Conolly et al 2017). This means there were 400,000 problem gamblers in Britain, and another half million who gambled dangerously. To his credit, Woolf has been a trustee of the Responsible Gambling Trust for many years. 
Second, there is the utilitarian iconoclast. In a way, he is the extreme case of the hyperliberal, who ends up being a libertarian who challenges everyday thinking. He operates as a controversialist, saying the unsayable, and jolting us out of our convictions. He pushes our everyday intuitions to the extremes, or goes to the extremes to show us that our everyday intuitions are wrong. This is the world of Julian Savulescu or John Harris or Peter Singer. Sitting on commissions or writing for lay readers, this philosopher has dedicated followers, but may not change public opinion as a whole. The utilitarian philosopher is particularly enraging to disabled people, because he legitimises prenatal diagnosis and other measures which seem threatening to those with disabilities; at the most extreme, he argues for euthanasia of newborns.

Third, there is the philosopher as oligarch. She takes her great technical prowess and goes to sit amongst the mighty, where she is as respected as she is In academic circles. She chairs parliamentary committees and public bodies. She moves beyond her area of professional expertise and talks about other topics of public policy, applying her toolkit of philosophical expertise wherever possible. She distrusts the media and the level of public debate: sometimes she seems to scorn lay people themselves. Her way of making a difference is to speak to the elites, and to become one of the elite. Mary Warnock or Onora O'Neil, or in earlier generation Isaiah Berlin, are examples of this tendency.

Fourth, there is the philosopher as radical. She is more humble than the oligarch. She uses philosophical thinking to deconstruct taken for granted assumptions - like the utilitarian, but not sharing the arid and narrow consequentialist calculus. She may not have allegiance to a single moral theory, by which all topics can be answered. She is less systematic, more provisional in her analysis. Like the hyper liberal, indeed like all these types, she clarifies areas of confusion, points out inconsistencies, deconstructs taken-for-granted assumptions. But she also turns her spotlight on, or applies her chisel to, other philosophers, and shows up their limitations or mistakes in their work. I think Bernard Williams often operated in this way. Mary Midgeley is someone who always has always done this: she has spoken truth to power, challenging the scientists or business people who may otherwise operate unchallenged in the public arena. 
There are undoubtedly other varieties of activist philosopher, and no doubt this typology should be refined and further sub-divided. It will be clear from my characterisation that I am partial. I have worked alongside and debated with all these types, and I think some are more useful, and some are more dangerous than others. Perhaps all these roles are necessary, and do some good in some circumstances. But I worry about the damage that the less humble varieties of academic philosopher can do. Perhaps they worry about the damage that my own insufficiently humble academic activist-ethicist might do, or has done. I would say that probably each of the ideal-types of academic activist philosopher can do a different type of damage in the public realm.

The more publicly esteemed the philosopher is, the more worrying I think them. I believe that questions of public policy are too complex to be left to moral philosophers. And I think moral philosophy is not always the most helpful tool for public policy makers. This is a huge topic, on which I only have space to say a couple of things, which have been said before, and may seem obvious anyway. But it seems helpful regularly to remind people of them, particularly philosophers themselves.

One obvious reason informing my thinking is that most moral questions do not have one answer. Otherwise moral philosophy would have ended by now. Instead, there are competing perspectives, and different arguments which can be given different weights. So the answer that Peter Singer gives to a public policy dilemma would usually be different to the answer that Michael Sandel might give. To listen to one and to ignore the other might be dangerous. They both have something to contribute, but it is not immediately obvious to a neutral party that one should be preferred on all questions.

But more widely than that, another difficulty is that moral expertise is not the only relevant expertise. Mostly public policy is about real people and what they should do, which relates to what they might do and could do and do do. Philosophy is not a universal multi-tool. We requires a bigger toolbox than simply philosophy (I was trying to think about whether the best simile was of philosophy as an awl or a hammer or a razor, but you can add your own analogy here).

So, given that many philosophers deploy consequentialist arguments, then some empirical knowledge of what might result from particular policy configurations would appear prima 
facie helpful. So, social or political research or expertise should supplement the normative reasoning. Economists often typify what groups of people get up to. All of these social scientists can help us understand how complex systems work.

The social world is not just about consequences and power and social relations and processes. It is also about meanings and beliefs and practices. When I want to understand those questions, I turn to an anthropologist, who has expertise in how different cultures operate on these terms. Sociologists and anthropologist can give insight into the wider cultural and social framework - the power and the meanings. The social world, at base, is about what real people actual do, as individuals or in crowds. So, a psychologist is required to understand how individuals think and how they might behave.

Without drawing on, or working with, all these different types of expertise, then the philosopher is not going to be a very good guide. In particular, the work of psychologists Daniel Kahmeman and Amos Tversky (summarised in Kahneman 2011) reminds us that individuals and groups do not behave as rationally and coherently as either the philosopher would hope, or the economist would assume: their thinking displays biases and is subject to fallacies.

\section{Interests and identities}

The word "interest" might be helpful here, because of its different usages in the English language. A philosopher, like any intellectual, is interested in many different topics. And public policy, in particular, is very interesting. It is interesting to deploy philosophical thinking as a contribution to these interesting questions. If an intellectual was uninterested in participating in public debate, it would seem at least a shame, and at worst, irresponsible in someone who work is usually supported, to a greater or lesser extent, with public money.

But individuals are not always disinterested, neutral observers, despite the claim of some philosophers to be able to take the perspective of an archangel (Hare, 1981). People may have a stake in a things. These interests are usually obvious, if they are properly declared. People may be being paid, or at least wined and dined, by one or other player in the 
controversy in question. Sometimes, this means they should recuse themselves.

Sometimes, they become compromised. Occasionally, an academic becomes guilty of corrupt practices.

Sometimes, an intellectual has an interest because of an ideological or religious position. For example, here I should declare an interest: I am a Quaker. For me, this means I am opposed to gambling, because I consider it profiting from another person's loss and I see that as immoral: I do not play the National Lottery, or engage in any other gambling. But I am inconsistent, because I have helped allocate funding from the National Lottery Charities Board and also from the Big Lottery Fund-supported DRILL programme. Separately, I have been involved with successful (and unsuccessful) applications to the Big Lottery Fund, as a researcher or as trustee of a voluntary organisation. So I am compromised in the debate on gambling, in various ways.

Sometimes, a philosopher or other intellectual has personal interests because it is a debate on disability and they have an impairment themselves or are the relative of someone else who has an impairment. Sometimes their impairment makes no difference to their thinking. But sometimes it makes a considerable difference. Disability can make the work of a bioethicist more useful, insightful, original and necessary. This is where Jackie Leach Scully (2008) talks about disability bioethics - the different standpoint and viewpoint that a disabled person who is also a bioethicist - or vice versa - can bring:

"doing this means working from people's experience of disability to see if and how it colors their perceptions, interpretations, and judgements of what is going on in moral issues, especially in moral issues that have direct relevance to disability and where differences in experiences of disability might be expected to have weight." (Scully, 2008, 1

But the ways in which disability makes a difference are complex, because disability is a multi-dimensional, scalar concept, which depends heavily on the wider context (Shakespeare, 2006). The experience of being a disabled person is multiple. It may be about having a particular diagnosis (e.g. MS) or a consequent functional limitation - being unable to walk or hear well. It may be about the cultural stigma or discrimination that often accompanies the limitation: society regards people with mental health conditions, In 
particular, in often prejudicial ways. It may be about the social barriers that one faces: the hearing loop that does not work, the lack of a ramp or elevator. It may be about the lack of social opportunities: the lack of health insurance, or employment. The experience of disability is the result of the interaction between the person with the health condition, and the wider social and cultural context. Therefore, just because a bioethicist is diagnosed with diabetes or a heart condition does not immediately make them disabled, or a disabled bioethicist. But perhaps if they live long enough, and experience enough, they might become one.

So, there is not one disability bioethics: there is a range. It would be greatly mistaken to try and read off ethical opinions from states of embodiment. For example, some people, who are close to people with genetic conditions, reject screening as disloyal or they believe a condition not to be incompatible with the good life. Others, who have seen the effects of genetic conditions, wish to avoid having a baby affected by that condition. Two people with the same impairment or illness may have a very different attitude to the ethical questions which biomedical interventions raise.

For example, attitudes towards prenatal testing for Spinal Muscular Atrophy (SMA) held by adults with the condition have been found to be linked to the severity of the symptoms they experience and time of symptom onset (Boardman, Young and Griffiths 2017). In a survey of over 80 individuals with SMA the majority were in favour of prenatal genetic screening for the condition. However, those with early onset SMA and more severe symptoms were less supportive of prenatal testing than those with late onset and milder symptoms. The group with the more severe types of SMA also viewed their experiences of disability more positively than those who had experienced life as a non-disabled person or had less significant symptoms. Individuals with relatively static impairments present from birth tend to adjust better to their condition and identify with it in comparison with those who have experienced an alternative life 'before disability' or experience periods of decline and change - being disabled is not an identity they want (Shakespeare 2006). For this group, prenatal testing is not viewed as a rejection of disabled people, rather a rejection of the negative aspects associated with impairment. This points to how a genetic condition or impairment is not always 'identity affecting', particularly if it has not been congenital (Edwards 1999). 
However, this nuanced and heterogenous approach to the relations between impairment status (or genetic status) and bioethical position is not evident in all the approaches to disability bioethics. I have written elsewhere of what I consider to be the more toxic impact of identity or minority group politics (Shakespeare 2013), following the critique of Nancy Fraser. Identity politics does play a very important role in mobilising a movement, and empowering individuals (Charlton). But I think that a misleading analogy is often made between gender, ethnicity and sexuality, on the one foot, and impairment, on the other. First, the evidence is that many people with impairments - perhaps $50 \%$ of people who would be considered to be disabled - do not identify as such. In other words, the salience of disability to personal identity differs. Impairments and other health conditions are not always identity-affecting (Edwards 1999).

Second, whereas gender, ethnicity and sexuality are almost always only problematic where social stigmatisation or discrimination makes life more difficult for people in the subaltern categories. That is to say, they are socially created problems. However, impairment and illness are almost always problematic, to some extent, and sometimes to a very great extent. As with gender, ethnicity and sexuality, society imposes a burden which makes everything more difficult - people are indeed disabled by society. But in the case of disability, many people are also disabled by their differences of body or mind. So impairment/disability is not necessarily something to be celebrated, there may be good reasons to try to prevent the onset of impairment, and it is understandable that some people take steps to detect impairments in the womb, and to terminate affected pregnancies. Not a move that everyone wants to make, and something that should always be a matter of personal conscience, within the parameters of the law, but a very different category of action to those that are directed against fetuses that are found to be female, for example.

However, as so often, my viewpoint here is controversial, and rejected by many within disability studies. So that means many people, activists and academics within the standpoint of disability identity politics, contest and oppose prenatal diagnosis and selective abortion. Even though most would support a woman's right to choose, there are suggestions that fetal characteristics should be a prohibited ground for termination: in other 
words, women can choose not to be pregnant, but not choose what fetus to be pregnant with.

\section{Conclusions}

I welcome the contribution of activists to bioethics, and think there should be more space for different voices. In particular, we need to hear the diverse voices of disabled people. We need more disabled people to have the training - whether in social science or in philosophy - to be able to take part in these debates. This is not necessarily about growing new cohorts of disabled academics - although that would be useful - but it could be about giving basic bioethics grounding to activists, so that more could participate confidently in debates, such as Peter Singer's famous debate with Harriet McBride Johnson.

I think bioethicists need also to be educated, whether by activists or by social scientists does not matter. They need to hear testimony about everyday lives of disabled people, so that their approaches reflect lived reality, not some imagined fantasy of what disability is like. For example, there is strong evidence that disabled people have a good quality of life. A good bioethicist would have researched this, so her ethical claims are rooted in empirical evidence, even if she does not gather that evidence herself.

I think we should be aware that just as there are multiple bioethicists with a range of views - not all bioethicists are Utilitarians or libertarians, only the loudest ones - so disabled people have a range of views on topics such as prenatal diagnosis and assisted suicide (Garland-Thompson 2012). We need to ensure all views are heard, not only those which accord with the current outlook of the disability rights movement. There are multiple disability bioethics. And some disabled people will do philosophy in a different way entirely (Carel). All are to be welcomed.

\section{References}

Boardman, F.K., P.J. Young \& F.E. Griffiths (2017) Impairment experiences, identity and attitudes towards genetic Screening: the views of people with Spinal Muscular Atrophy. Journal of Genetic Counseling. online ahead of print. 
Brock DW Truth or consequences: the role of philosophers in policy-making, in Kuhse $\mathrm{H}$, Singer P (eds) Bioethics: an anthology (second edition) Blackwell, Malden, 2006, pp 714 Conolly, A. Fuller E, Sonaal H, Wardle, H. (2017) Gambling Behaviour in Britain 2017: evidence from England, Scotland and Wales, NatCen report for the Gambling Commission, London.

Garland-Thomson, R (2012) The case for conserving disability, Bioethical Inquiry DOI $10.1007 / \mathrm{s} 11673-012-9380-0$

Haidt, J . (2001). The emotional dog and its rational tail: A social intuitionist approach to moral judgment. Psychological Review. 108, 814-834

Hare, R. M. (1981). Moral Thinking. Oxford: Oxford University Press

Kahneman, D. (2011) Thinking Fast and Slow, New York: Farrar, Straus and Giroux.

Moreno JD Ethics consultation as moral engagement, in Kuhse H, Singer P (eds) Bioethics: an anthology (second edition) Blackwell, Malden, 2006, pp 707-714

Morris, J. (1991) Pride Against Prejudice, Women's Press, London.

Oliver, M (1990) The Politics of Disablement, Macmillan, Basingstoke.

Scully, JL (2008) Disability Bioethics: moral bodies, moral differences. Lanham MD, Rowman and Littlefield.

Shakespeare, T, Thompson, S, Wright, M.J. (2010) No laughing matter: medical and social experiences of restricted growth, Scandinavian Journal of Disability Research, 12, 1: 19-31

Shakespeare, T (2006) Disability Rights and Wrongs, Routledge, London.

Shakespeare, T (2013) Disability Rights and Wrongs Revisited, Routledge, London.

Shakespeare, T (2014) Nasty brutish and short: on the predicament of disability and embodiment, in Bickenbach J, Felder F and Schmitz B (eds) Disability and the Good Human Life, Cambridge: Cambridge University Press 